\title{
Dietary sugar and Crohn's disease
}

\author{
K.W. HEATON, MA, MD, FRCP
}

\begin{abstract}
Epidemiologically, Crohn's is a disease of modern Western civilization. The diet of the Western world is highly processed. Many surveys have shown that patients with Crohn's disease habitually eat more than the average amount of some processed foods, namely those rich in added sugars. Sugar rich meals lead to increased intestinal permeability which is a feature of Crohn's disease patients and of their relatives. Replacement of added sugars and fibre depleted cereals by whole or unrefined foods is well tolerated by most patients with Crohn's disease and it may reduce their need for surgery and hospital treatment. Until the pathogenesis of the disease is clarified the role of dietary factors remains debatable but the evidence incriminating a sugar rich highly processed diet in the etiology of Crohn's disease, albeit indirect, is enough to justify further research in this area. Can J Gastroenterol 1988; 2(1): 41-44
\end{abstract}

Key Words: Crohn's disease, Diet, Sugar

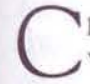
ROHN'S DISEASE IS A DISEASE OF Westernized countries (1) and is more common in northern Europe than southern Europe (2). Its prevalence in Europe and USA increased in the middle part of this century, at least until the mid-1970s (3). These epidemiological facts imply that environmental factors are important in causing Crohn's disease. Because these factors are unknown the possibility exists that the disease is linked in some way to the eating habits characteristic of the mid-20th century.

\section{CASE CONTROL STUDIES}

Case control studies are an accepted way of looking for dietary causes of a disease. Patients with the disease are matched with healthy controls for

Correspondence: $\operatorname{Dr}$ K.W. Heaton, University Department of Medicine, Bristol Royal Infirmary, Bristol BS2 8HW, England. Telephone (0272)230000

known determinants of the disease (such as age and race) and both groups are then questioned about their habitual diet in the hope that present eating habits reflect pre-illness habits. If the disease itself could modify eating habits the study should be limited to recently diagnosed patients.

The only reported case control study of Crohn's disease in which all the patients were newly diagnosed and in which dietary intakes were comprehensively analyzed is that of Thornton and colleagues (4). Two differences emerged between the patients and controls. The patients ate more 'refined' or added sugars, indeed, nearly twice as much; they also ate less fruit and vegetables so their intake of dietary fibre was slightly lower. There were no differences in the intake of starch, fat, protein or alcohol. The excess sugar was taken not only as table sugar added to foods and drinks but also as sugars consumed in prepared foodstuffs. This invisible sugar is, nowadays, responsible for the majority of the intake of refined or added sugars (5). 
Interest in the possible dietary causes of Crohn's disease began in 1976 with two reports from Germany of high intakes of sugar, based on selfadministered postal questionnaires $(6,7)$. Since then, no less than 13 case control studies of sugar intake have been reported, using several different methodologies (4,8-18). All 15 studies have found high sugar intakes in patients with Crohn's disease (Table 1).

The only other consistent finding in these studies is that, when looked at, the intake of fresh fruit has been lower in the patients than in the controls $(4,11,18)$. In the present author's study (4), the median intake of raw fruit and vegetables in patients was only $26 \%$ of that in the controls.

Sceptics can point out the imprecision of dietary methods and the impossibility of getting hard data on past eating habits. They cannot, however, deny the unanimity of the findings, which is quite remarkable and cannot be explained by inaccurate methods.

\section{WHY ARE EATING HABITS DIFFERENT IN PATIENTS WITH CROHN'S DISEASE?}

Three explanations have been offered as to why eating habits differ between Crohn's patients and controls. First, patients may eat more sugar and sugary foods because they have a high taste threshold for sweetness; this in turn could be due to zinc deficiency which is known to occur in Crohn's disease and which impairs taste. This hypothesis has been thoroughly tested and disproved. $\mathrm{Pa}$ tients with Crohn's disease have sim. ilar taste thresholds to healthy controls $(17,19)$. Also there is no correlation between sugar intake and the plasma zinc concentration (17).

A second suggestion is that, as the disease develops, patients slowly and unconsciously change their food intake to counter symptoms such as weight loss, diarrhea and abdominal pain. This seems plausible, but the weight of evidence is against it. If it were true, patients with ulcerative colitis, who have similar symptoms, should also have high sugar intakes. But when such patients were investi-

TABLE 1

Published data on sucrose (added sugar) intake in groups of patients with Crohn's disease and in healthy controls

\begin{tabular}{|c|c|c|c|c|}
\hline City & $\begin{array}{l}\text { Number } \\
\text { of patients }\end{array}$ & $\begin{array}{l}\text { Mean sucrose intake } \\
\text { Crohn's vs controls }\end{array}$ & Method & Reference \\
\hline Marburg & 63 & $57 \%$ more & Postal Q & 6 \\
\hline Düsseldorf & 34 & $109 \%$ more & Postal Q & 7 \\
\hline Würzburg & 20 & $\begin{array}{c}\text { 'Heavy consumers' } \\
35 \% \text { vs } 5 \%\end{array}$ & $\begin{array}{l}\text { 7-day } \\
\text { record }\end{array}$ & 8 \\
\hline Cardiff & 100 & $\begin{array}{l}57 \% \text { more in drinkst } \\
87 \% \text { more on cereals }\end{array}$ & Dietary history & 9 \\
\hline Manchester & 68 & $43 \%$ moret & Dietary history & 10 \\
\hline Bristol & $30 \neq$ & $88 \%$ more & Dietary history & 4 \\
\hline Würzburg & 35 & $71 \%$ more & 7-day recall & 11 \\
\hline Tel Aviv & 27 & $119 \%$ more $*$ & $\begin{array}{l}\text { 7-day recall and } \\
\text { dietary history }\end{array}$ & 12 \\
\hline Cardiff & 120 & $77 \%$ more & Postal Q & 13 \\
\hline Cardiff & 16 & $220 \%$ more ${ }^{*}+$ & 5-day weighed record & 14 \\
\hline $\begin{array}{l}\text { Birmingham } \\
\text { \& Cardiff }\end{array}$ & 32 & $150 \%$ moret & Postal Q & 14 \\
\hline Tübingen & NS & 'Much more' & NS & 15 \\
\hline Örebro & 30 & $41 \%$ more & Dietary history & 16 \\
\hline Cardiff & 70 & $124 \%$ moret & Dietary history & 17 \\
\hline Milan & 109 & 'Higher'§ & NS & 18 \\
\hline
\end{tabular}

- During illness; even more sugar eaten before illness; +Visible sugar only; $¥$ Newly diagnosed patients, 0 Questionnaire; NS Not stated; §Relative risk in high versus low consumers of packet sugar and of sweets 3.41 and 3. 34 , respectively

gated, no difference was found between their sugar intakes and those of controls in two out of three studies $(18,20,21)$. Also, when patients with Crohn's disease have been asked whether their eating habits have changed since they became ill they have, in four out of five reports, stated that they have cut down on sugar, not increased it $(6,7,12-14)$. To quote Kasper and Sommer (11), "the excessive consumption of sweets, pastries and sugar sweetened beverages had become a habit in all many years before onset of symptoms". There are, in fact, no grounds for assuming that symptoms are relieved by replacing fruit with sugary foods. On the contrary, fruit is usually well tolerated (22) and a high sugar intake may even worsen symptoms (23).

The third explanation is that a sugar rich diet increases the risk of developing Crohn's disease. This idea is also consistent with the epidemiology of the disease.

\section{HOW COULD A SUGAR RICH DIET FAVOUR THE DEVELOPMENT OF CROHN'S DISEASE?}

Since the pathogenesis of Crohn's disease is unknown one can only speculate as to how a sugar rich diet could encourage it to develop. There are, however, three possibilities consistent with current limited knowledge.

First, sugars are osmotically active. Sucrose is the only osmotically active substance ingested by human beings in concentrated form and in large quantities (more than $10 \mathrm{~g}$ daily). A candy bar or a slice of cake may well contain 30 to $40 \mathrm{~g}$ sucrose. Hypertonic solutions increase the permeability of the intestinal mucosa (24-26). Indeed, normal mucosa becomes as permeable as the damaged mucosa of celiac disease patients when it is exposed to the stress of a hypertonic drink (26). Increased permeability of the small intestine is a well known feature of patients with Crohn's disease (27). It has also been reported in their relatives (28), which suggests that increased permeability may pre-date the disease. The precise significance of increased permeability remains to be established but, if it allows repeated absorption of antigens from the gut lumen, this could perhaps lead to an inflammatory response in the sensitized gut wall.

Secondly, a high sucrose intake might induce changes in the intestinal flora or their metabolism, for example 
increased bile acid degradation, with the formation of toxic metabolites. Addition of $120 \mathrm{~g}$ sucrose daily to the diet has been reported to increase the excretion of secondary, ie, degraded, bile acids and to enhance intestinal fermentation in normal volunteers (29). Whole gut transit time was also lengthened.

Thus, a high intake of sugar can alter gut physiology in at least two ways which are potentially harmful. Much more research is needed, however. Among other things we need to know what a sugar rich diet does to the gut's defences against microbial invasion. Because a sugar rich diet tends to be low in fruit and other 'whole' foods it is relatively deficient in vitamins and minerals, including trace elements (30), and low intakes of vitamin C, pyridoxine, zinc and linoleic acid may lead to impaired function of T lymphocytes (31). This is of interest because T lymphocyte function tends to be abnormal in Crohn's disease patients (32).

\section{THERAPEUTIC RESPONSE TO LOW SUGAR DIETS}

The fact that an agent or regimen cures a disease does not usually mean that the disease is caused by the lack of that agent or by the opposite of that regimen. However, if a chronic disease is ameliorated by abstaining from a habit which was prominent while the disease was developing, then it may be reasonable to suspect a causative relationship between the habit and the disease. Thus, it is pertinent to review the therapeutic effects of a low sugar diet in Crohn's disease.

In 1972 the author began, on empirical grounds, to advise his patients with Crohn's disease to exclude refined carbohydrates, otherwise known as fibre depleted foods, from their diet. Instead of sugar and white flour, and products made from them, patients were advised to eat fruit and wholemeal flour and products made from them. Although this regimen involved an increase in dietary fibre intake this was not the purpose of the diet, rather it was simply to replace highly processed foods with more 'nat- ural' ones. The diet did not include bran or any other concentrated preparation of fibre. Treatment was conventional in every other respect.

In 1979, the results of using this diet in 32 consecutive patients with Crohn's disease were published (33). In comparison with a closely matched group of 32 patients from other clinics in Bristol the diet-treated patients had fared significantly better. Over a mean follow-up of 52 months they had spent only 111 days in hospital compared with 533 days in the control group and had required only one intestinal operation compared with five in the control group. This was not a randomized, prospective trial and the better progress of the diet-treated patients may have been due to some other unidentified difference in management or to a difference in the type of case referred to this clinic from the other Bristol clinics.

A very small randomized trial was reported from Brunswick in 1981 (23). When five patients with moderately active disease were given a sugar rich diet, four became worse whereas only one of five patients became worse who were allocated to a sugar free, high protein diet.

A team at St Mark's Hospital, London, England has recently reported a randomized trial involving $352 \mathrm{pa}$ tients with mildly active or inactive Crohn's disease (34). One hundred and ninety were prescribed a diet of the type used in Bristol. The rest continued with their usual diets. At the end of a 24 month follow-up there were fewer surgical operations and hospital admissions in the group on the low sugar diet but the differences did not reach statistical significance. It seems churlish to criticize this mammoth study. In may ways it was scrupulously correct. However, its failure to show a significant difference needs close examination. The average reduction in sugar intake in the test group was only $53 \mathrm{~g}$ per day and there was an $11 \mathrm{~g}$ per day reduction in the control group. The number of operations was rather small, even in the control group $14.3 \%$ per year), suggesting that the volunteers in this study were patients with unusually benign disease. In such patients it might be difficult or impossible to show benefit. The patients in the Bristol and Brunswick studies were unselected and had more active dis. ease.

Thus, it remains unproven that a diet low in refined sugars is beneficial in the treatment of mildly active or inactive Crohn's disease but the author (although biased) believes it is helpful and still uses it; certainly, it does no harm.

A beneficial effect is not necessarily at variance with the proven benefit from an elemental diet (which is rich in sugars) in active Crohn's disease (35). Different phases of a disease often require different treatments.

\section{REFERENCES}

1. Trowell HC. Ulcerative colitis and Crohn's disease. In: Burkitt DP, Trowell HC, eds. Refined Carbohydrate Foods and Disease. Some Implications of Dietary Fibre. London: Academic Press, 1975: 135-40.

2. Sonnenberg A. Geographic variation in the incidence of and mortality from inflammatory bowel disease. Dis Colon Rectum 1986; 29: 854-61.

3. Sonnenburg A. Mortality from Crohn's disease and ulcerative colitis in England, Wales and the US from 1950 to 1983. Dis Colon Rectum 1986; 29:624-9.

4. Thornton JR, Emmett PM, Heaton KW. Diet and Crohn's disease: characteristics of the pre-illness diet. Br Med J 1979:2: 762-4.

5. Rugg-Gunn AJ, Hackett AF, Appleton DR, Moynihan PJ. The dietary intake of added and natural sugars in 405 English adolescents. Hum Nutr Appl Nutr 1986; 40A: 115-24.

6. Martini GA, Brandes JW. Increased consumption of refined carbohydrates in patients with Crohn's disease. Klin Wschr 1976; 54; $367-71$.

7. Miller B, Fervers F, Rohbeck R, Strohmeyer G. Zuckerkonsum bei Patienten mit Morbus Crohn. Verhandl Deutsch Ges Inn Med 1976; 82: 922-4.

8. Kasper H, Rabast U, Sommer H, Ehl M. Untersuchungen zur Höhe des Rohfaserverzehrs bei Gesunden und bei Erkrankungen des Gastrointestinaltraktes. Verhandl Deutsch Ges Inn Med 1977; 83: 464-7.

9. Mayberry JF, Rhodes J, Newcombe RG. Breakfast and dietary aspects of 
Crohn's disease. Br Med J 1978;2:1401.

10. Graham WB, Torrance B, Taylor TV. Breakfast and Crohn's disease. Br Med J 1978; 2: 768.

11. Kasper H, Sommer H. Dietary fiber and nutrient intake in Crohn's disease. Am J Clin Nutr 1979; 32: 1898-901.

12. Silkoff K, Hallak A, Yegena L, et al. Consumption of refined carbohydrate by patients with Crohn's disease in Tel-Aviv-Yafo. Postgrad Med J 1980; 56: 842-6.

13. Mayberry JF, Rhodes J, Newcombe RG. Increased sugar consumption in Crohn's disease. Digestion 1980; 20: 323-6.

14. Mayberry JF, Rhodes J, Allan R, et al. Diet in Crohn's disease. Two studies of current and previous habits. Dig Dis Sci 1981; 26: 444-8.

15. Naujoks-Heinrich S, Grossman S, Gottschalk S, Förster S, Goebell H, Malchow H. Dietary habits in Crohn's disease. In: 2 nd Symposium on Crohn's Disease, Hemmenhofen, 1982. Cited by Lorenz-Meyer $\mathrm{H}$ and Brandes JW. Gibt es einer diätetische Behandlung des Morbus Crohn in der Remission? Dtsch Med Wochenschr 1983; 108: 595-7.

16. Jänerot $G$, Järnmark I, Nilsson K. Consumption of refined sugar by patients wich Crohn's disease, ulcerative colitis, or irritable bowel syn. drome. Scand J Gastroenterol 1983; 18: 999-1002.

17. Penny WJ, Mayberry JF, Aggett PJ, Gilbert JO, Newcombe RG, Rhodes J. Relationship between trace elements, sugar consumption, and taste in Crohn's disease. Gut 1983; 24: 288-92.

18. Panza E, Franceschi S, La Vecchia C, et al. Dietary factors in the aetiology of inflammatory bowel disease. Ital J Gastroenterol 1987; 19:204-9.

19. Kasper H, Sommer H. Taste thresholds in patients with Crohn's disease. J Hum Nutr 1980; 34: 455-6.

20. Thornton JR, Emmett PM, Heaton KW. Diet and ulcerative colitis. Br Med J 1980; 1: 293-4.

21. Martini GA, Stenner A, Brandes WJ. Diet and ulcerative colitis. Br Med J 1980; 1: 1321.

22. Levenstein S, Prantera C, Luzi C, D'Ubaldi A. Low residue or normal diet in Crohn's disease: a prospective controlled study in Italian patients. Gut $1985 ; 26: 989-93$.

23. Brandes J-W, Lorenz-Meyer H. Zuckerfreie Diät: eine neuer Perspektive zur Behandlung des Morbus Crohn? Eine randomisierte, kontrollierte Studie. Z Gastroenterol 1981; 19:1-12.

24. Laker MF, Menzies IS. Increase in human intestinal permeability following ingestion of hypertonic solutions. J Physiol 1977; 265: 881-94.

25. Maxton DG, Bjarnason I, Reynolds AP, Catt SD, Peters TJ, Menzies IS. Lactulose, ${ }^{51} \mathrm{Cr}$-labelled ethylenediaminetetra-acetate, L-rhamnose and polyethylene glycol 500 as probe markers for assessment in vivo of human intestinal permeability. Clin Sci 1986; 71: 71-80.

26. Wheeler PG, Menzies IS, Creamer B. Effect of hyperosmolar stimuli and coeliac disease on the permeability of the human gastrointestinal tract. Clin Sci Mol Med 1978; 54: 495-501.

27. Bjarnason 1, O'Morain C, Levi AJ, Peters T]. Absorption of 51 chromium-labelled ethylenediaminetetraacetate in inflammatory bowel disease. Gastroenterology 1983; 85: $318-22$.

28. Hollander D, Vadheim CM,
Brettholz E, Petersen GM, Delahunty $T$, Rotter JI. Increased intes. tinal permeability in patients with Crohn's disease and their relatives. A possible etiologic factor. Ann Intern Med 1986; 105: 883-5.

29. Kruis W, Forstmaier G, Scheurlen C. Stellaard F, Paumgartner G. Influence of diets high and low in refined sugar on stool qualities, gastrointestinal transit time and fecal bile acid excretion. Gastroenterology 1987; 92: 1483. (Abst)

30. Heaton KW, Emmett PM, Henry $\mathrm{CL}$, Thornton JR, Manhire A, Hartog M. Not just fibre - the nutritional consequences of refined carbohydrate foods. Hum Nutr Clin Nutr 1983; 37C: $31-5$.

31. Horrobin DF, Manku MS, Oka M, et al. The nutritional regulation of $\mathrm{T}$ lymphocyte function. Med Hypotheses $1979 ; 5: 969-85$.

32. Kraft SC. Inflammatory bowel disease (ulcerative colitis and Crohn's disease). In: Asquith P, ed. Immunology of the Gastrointestinal Tract. Edinburgh: Churchill Livingstone, 1979: 95-128.

33. Heaton, KW, Thornton JR, Emmett PM. Treatment of Crohn's disease with an unrefined-carbohydrate, fibre-rich diet. Br Med J 1979; 2: $764-6$.

34. Ritchie JK, Wadsworth J, Lennard. Jones JE, Rogers E. Controlled multicentre therapeutic trial of an unrefined carbohydrate, fibre rich diet in Crohn's disease. Br Med J 1987; 295: 517-20.

35. O'Morain C, Segal AW, Levi AJ. Elemental diet as primary treatment of acute Crohn's disease: a controlled trial. Br Med J 1984; 288: 1859-62.

\section{Clinical quiz - Answers}

\section{ESOPHAGUS}

1. Indications for surgery in reflux esophagitis

Uncontrollable hemorrhage secondary to erosive esophagitis Resistent esophageal ulcer

Stricture (nonresponding to bougienage)

Barrett's esophagus with dysplasia

Recurring aspiration-induced pulmonary disease

Intractibility of symptoms (relative indication)

\section{Features of typical motility pattern in patients with well established achalasia}

Upper esophageal sphincter normal

Lack of primary peristaltic waves; small amplitude simultaneous waves
Resting pressure elevated in body

Lower esophageal sphincter pressure elevated, fails to fall to zero with swallowing

Hypersensitivity to cholinergics

3. Complications of endoscopic sclerotherapy of esophageal varices

Local mechanical

Ulceration

Stricture and dysphagia

Pleural effusions

Esophageal perforation

Severe chest pain due to mediastinitis

General

Transient bacteremia

Acute respiratory failure 


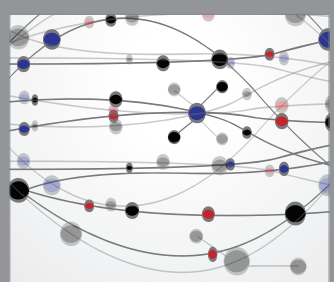

The Scientific World Journal
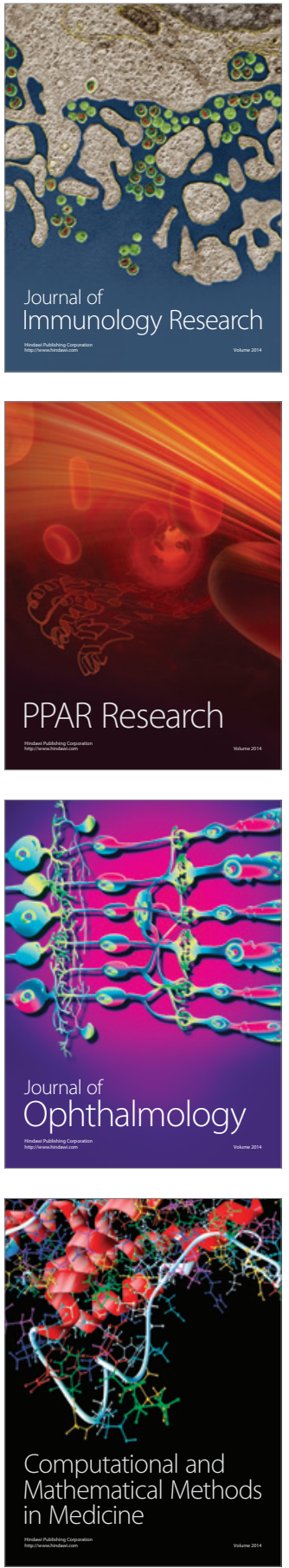

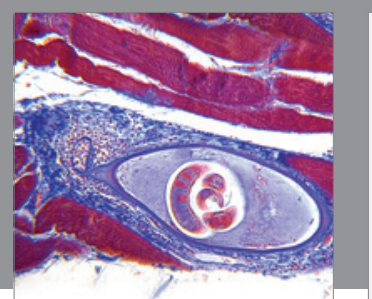

Gastroenterology Research and Practice

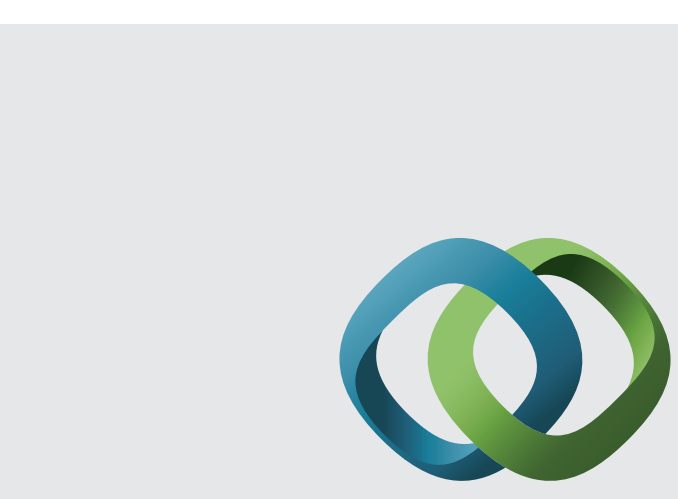

\section{Hindawi}

Submit your manuscripts at

http://www.hindawi.com
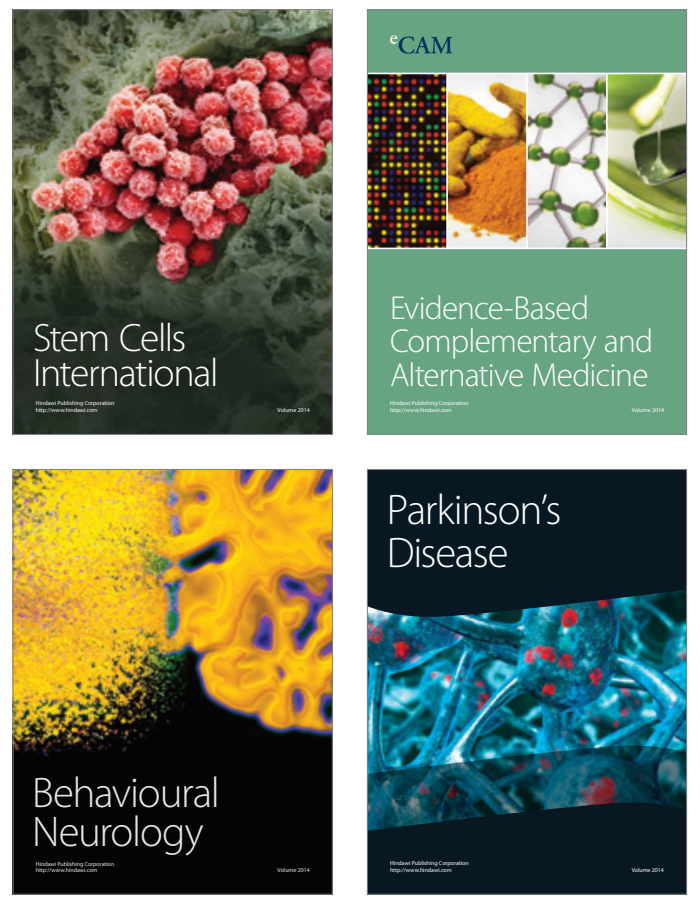
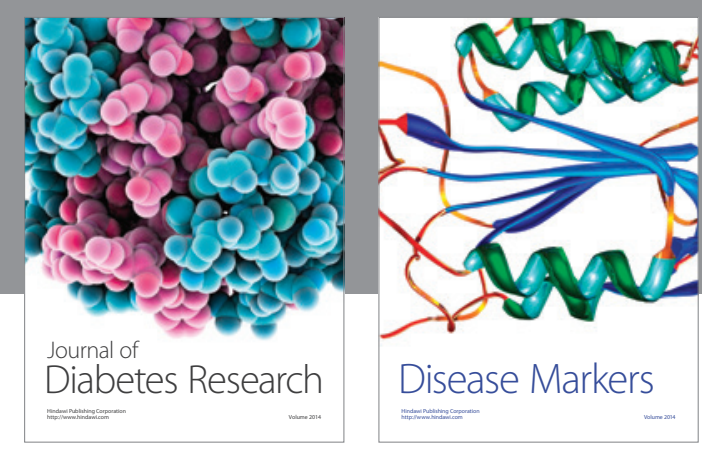

Disease Markers
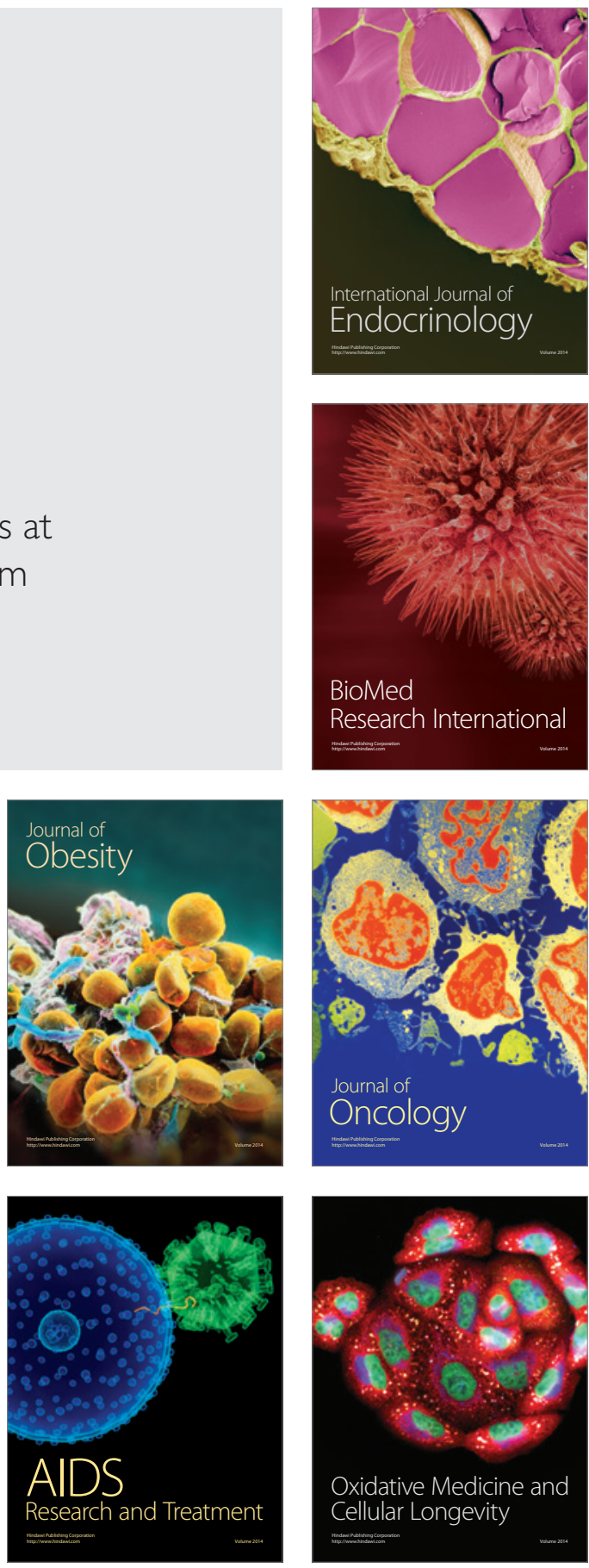